\title{
Construction of self-assembled nanogel as mulitenzyme mimics for bioresponsive tandem- catalysis imaging
}

\author{
Xianmeng Xia ${ }^{1}$, Xia Wang ${ }^{1 *}$, Xiaoke $\mathrm{Han}^{1}$, Meiyuan $\mathrm{Qi}^{1}$, Ya Gao ${ }^{2,3}$, Jiangnan Liao ${ }^{2,3}$, Xingyue $\mathrm{He}^{1}$, \\ Kai Pan ${ }^{1}$, Qian Cheng ${ }^{2,3}$ and Qigang Wang ${ }^{1 *}$
}

\begin{abstract}
The self-assembled phospholipid- or cytosolassociated multienzyme complexes constitute necessary components of the foundation of life. As a proof of concept, metalcoordinated supramolecular nanogels (MCSGs) have been designed, with the self-assembly of di-lysine coordinated iron $\left(\mathrm{Fe}(\mathrm{Lys})_{2}\right)$-functionalized peptide gelators on the interface by an in situ amidation-induced protonation process. The monoatomic and highly dispersed active centers of $\mathrm{Fe}(\mathrm{Lys})_{2}$ offered the nanogel mimics with excellent reaction rates due to the high density and nano compartmental structure similar to the natural matrix-associated multienzyme complex. $\mathrm{SiO}_{2} @$ MCSGs show both superoxide dismutase (SOD) activity and peroxidase (POD) activity, and the higher activities compared with the activity of free $\mathrm{Fe}(\mathrm{Lys})_{2}$ molecules can be detected. After loading the substrate 2,2'-azinobis-(3-ethylbenzthiazoline-6-sulphonate) (ABTS), $\mathrm{SiO}_{2} @ \mathrm{MCSG}^{\mathrm{ABTS}}$ can responsively convert $\mathrm{O}_{2}^{-\cdot}$ in the tumor microenvironment into $\mathrm{H}_{2} \mathrm{O}_{2}$ intermediates and then tandem catalyze the oxidization of ABTS for contrast photoacoustic (PA) imaging of tumor by the SOD-POD mimic activity, showing their great potential as the efficient enzymatic agents for pathological theranostics.
\end{abstract}

Keywords: nanogel, self-assembly, multienzyme mimics, photoacoustic imaging

\section{INTRODUCTION}

Self-assembly, a process prevalent in nature, plays important roles in biology, from maintaining the integrity of cells to performing cellular functions and inducing abnormalities that cause diseases [1-4]. Extracellular matrix (ECM) assembly is a critical and tightly regulated process in tissue repair. In the process of matrix assembly, mul- tivalent ECM proteins are induced to self-associate and interact with other ECM proteins to form fibrillar networks [5]. Various proteins such as collagens, laminins, proteoglycans, and remodeling enzymes constitute the ECM, playing the key role in tissue architecture and homeostasis [6]. Actually, enzymes usually perform their biological functions in a volume (cytoplasm)- or surface (membrane)-confined environment [7]. Many cellular reactions within metabolic pathways are catalyzed by matrix-associated multienzyme complexes, but not via the free enzymes. Enzymes, together with the process of self-assembly, constitute necessary components of the foundation of life on the nanometer scale [8-10].

Substantial research efforts have been directed to the development of enzyme-encapsulated self-assembled microstructures, such as liposomes [11], microcapsules $[12,13]$, polymersomes $[14,15]$, lipid-stabilized aqueous droplets [16] or protein-assembled virus-like structures $[17,18]$, as confined organized microenvironments for mimicking biological functions [19-22]. The vital effects of microenvironmental organization would reveal implications for the high efficiency, specificity, and regulation of metabolic pathways.

As typical ECM mimics, supramolecular hydrogels made of the self-assembled low-molecular-weight compounds (i.e., gelators) can integrate multienzyme proteins or active centers through noncovalent interactions $[23,24]$. Herein, as a proof of concept, the enzyme mimicfunctionalized peptide gelators have been designed. Detailedly, the tripeptide gelators have been first formulated and designed, by considering the hydrophobic assembly force and the hydrophilic modification group [25-27].

\footnotetext{
${ }^{1}$ School of Chemical Science and Engineering, Tongji University, Shanghai 200092, China

${ }^{2}$ Institute of Acoustics, School of Physics Science and Engineering, Tongji University, Shanghai 200092, China

${ }^{3}$ The Key Laboratory of Spine and Spinal Cord Injury Repair and Regeneration, Ministry of Education, Tongji University, Shanghai 200070, China

* Corresponding authors (emails: 15174@tongji.edu.cn (Wang X); wangqg66@tongji.edu.cn (Wang Q))
} 
The peptide NapFFE (Nap-Phe-Phe-Glu) was therefore synthesized (Fig. S1) and further connected to enzyme mimics, di-lysine-coordinated iron $\left(\mathrm{Fe}(\mathrm{Lys})_{2}\right)$ molecules. The amino group at one end can facilitate the successful grafting onto the peptide monomer (NapFFE-Fe(Lys) $)_{2}$ ), while the remaining amino group at the other end can be used for subsequent protonation-induced self-assembly. Based on the good chemical stability, biocompatibility, easy modification and no special catalytic influence with the enzyme mimics, the $\mathrm{SiO}_{2}$ nanoparticle has been selected as the inorganic core, and the self-assembled metalcoordinated supramolecular nanogel (MCSG) mimics can be therefore constructed on the nano-interface $\left(\mathrm{SiO}_{2} @\right.$ MCSGs), as shown in Scheme 1.

The self-assembly hydrogelation of $\mathrm{SiO}_{2} @ M C S G s$ nanogel mimics was realized by the amidation-induced protonation process. The interfacial decrease of $\mathrm{pH}$ to 6.5 during the reaction between carboxylic modified silica $\left(\mathrm{SiO}_{2}-\mathrm{COOH}\right)$ and the amino group of NapFFE-Fe(Lys $)_{2}$ monomer leads to the deposition of peptide on the sur- face of nanoparticles, and thus the resultant in situ selfassembled nanogel mimics were obtained due to $\pi-\pi$ stacking of hydrophobic naphthalen and the Phe group in the hydrogelators. The monoatomic and highly dispersed active centers of $\mathrm{Fe}(\mathrm{Lys})_{2}$ facilitate the self-assembled nanogel mimics with excellent reaction rates due to the high density and nano compartmental structure of enzyme mimics like the matrix-associated multienzyme complex structure. $\mathrm{SiO}_{2} @ M C S G s$ show both superoxide dismutase (SOD) activity and peroxidase (POD) activity similar to natural SOD (Fig. S2) and horseradish peroxidase (HRP). After loading the substrate 2,2'-azinobis-(3ethylbenzthiazoline-6-sulphonate) (ABTS), $\quad \mathrm{SiO}_{2} @$ MCSGs ${ }^{\text {ABTS }}$ can responsively convert $\mathrm{O}_{2}^{-{ }^{-}}$in the tumor microenvironment into $\mathrm{H}_{2} \mathrm{O}_{2}$ intermediates by the SOD mimic activity, then tandem oxidize the ABTS into its oxidized form with strong absorption in the near-infrared (NIR) band in the presence of $\mathrm{H}_{2} \mathrm{O}_{2}$ by the POD mimic activity. These self-assembled $\mathrm{SiO}_{2} @ M C S G{ }^{\mathrm{ABTS}}$ nanogel mimics show great potential as the responsive enzymatic

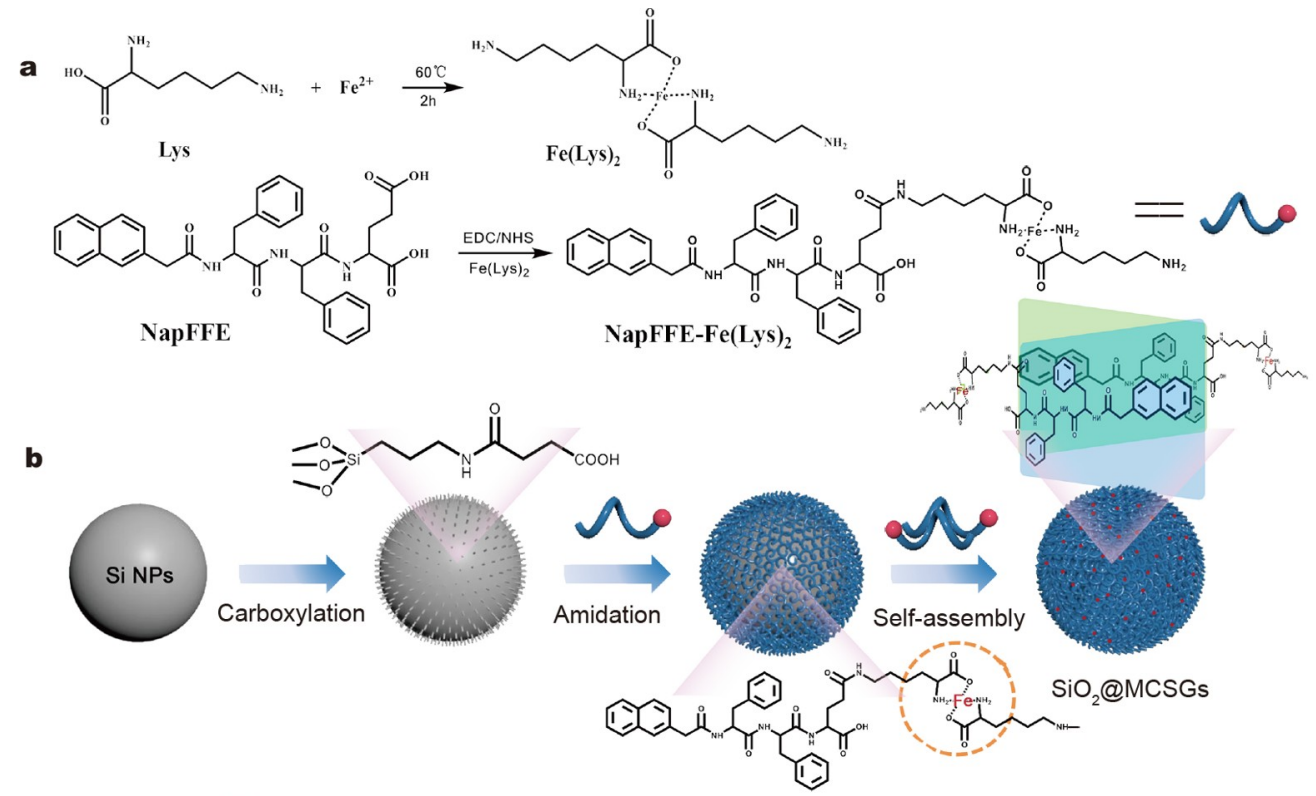

c

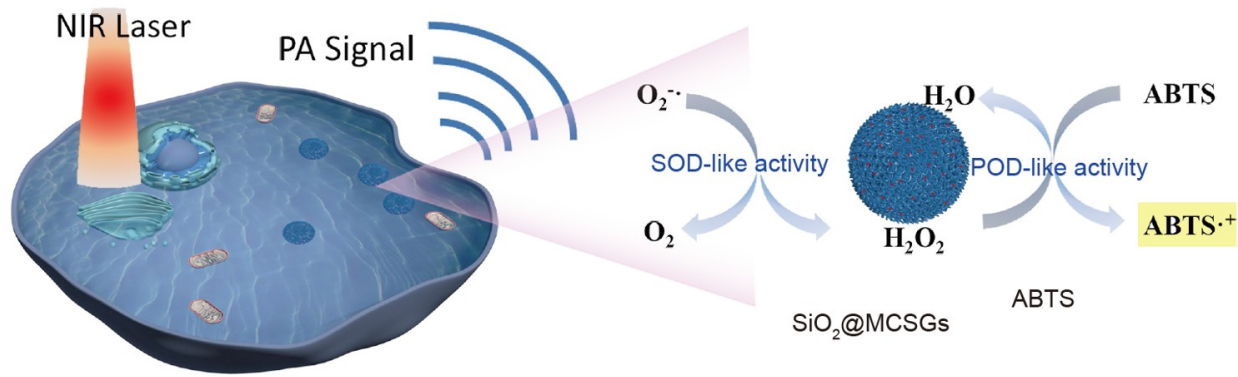

Scheme 1 (a) Synthesis of the NapFFE-Fe(Lys) . (b) Preparation of the $\mathrm{SiO}_{2} @ M C S G s$. (c) Schematic representation of multi-catalyzed PA imaging by $\mathrm{SiO}_{2} @ \mathrm{MCSG}^{\mathrm{ABTS}}$. 
agents for photoacoustic (PA) imaging of tumor [11,28].

\section{RESULTS AND DISCUSSION}

\section{Characterization of $\mathrm{SiO}_{2} @$ MCSGs}

As shown in Figs 1 and 2, the structure and physicochemical properties of $\mathrm{SiO}_{2} @ \mathrm{MCSG}$ were investigated by scanning electron microscopy (SEM), transmission electron microscopy (TEM), scanning TEM (STEM), energy dispersive X-ray (EDX) spectroscopy mapping, dynamic light scattering (DLS), Fourier transform infrared spectroscopy (FT-IR) measurements and thermogravimetry (TG) analysis.

As shown in the typical TEM and SEM images in Fig. 1a and b, $\mathrm{SiO}_{2} @ M C S G$ have a rougher surface compared with that of the $\mathrm{SiO}_{2}$ cores, and the significant core-shell structures with MCSG nanoshell of about $10 \mathrm{~nm}$ can be observed around the black $\mathrm{SiO}_{2}$ core. More obvious shell structure can be observed in STEM as shown in Fig. 1c. The major elements including Si, O, C and $\mathrm{Fe}$ can be detected by EDX. Importantly, the monodispersed $\mathrm{Fe}$ as the active center of self-assembled nanogel mimics has been detected. Furthermore, the selfassembly hydrogelation of $\mathrm{SiO}_{2} @ M C S G$ s has been verified by the increased average hydrodynamic sizes and the changes of the zeta potential during the preparation (Fig. 2a and b). The X-ray photoelectron spectroscopy (XPS) result showed the existence of $\mathrm{S}$, which proved the successful load of ABTS (Fig. S3). The typical characteristics of $\mathrm{Fe}(\mathrm{II})$ and $\mathrm{Fe}(\mathrm{III})$ in $\mathrm{SiO}_{2} @ M C S G{ }^{\mathrm{ABTS}}$ can be observed in the Fe 2p XPS spectra (Fig. S4). The peaks appearing at about 710.8 and $724.0 \mathrm{eV}$ were assigned to $\mathrm{Fe}(\mathrm{II})$, and that at $712.3 \mathrm{eV}$ corresponded to $\mathrm{Fe}(\mathrm{III})$, whereas other peaks were assigned as satellite peaks [29]. The FT-IR characteristic peak at $1642 \mathrm{~cm}^{-1}(\mathrm{C}=\mathrm{O}$ stretching), $3274 \mathrm{~cm}^{-1}$ (N-H stretching), $1062 \mathrm{~cm}^{-1}$ ( $\mathrm{Si}-\mathrm{O}$ stretching) and $949 \mathrm{~cm}^{-1}$ (Si-OH bending) of the silica structure also verify successful grafting procedures (Fig. 2c) [30]. The components of the hydrogel layer in $\mathrm{SiO}_{2} @ M C S G s$ were further analyzed by TG with a 30.5\%
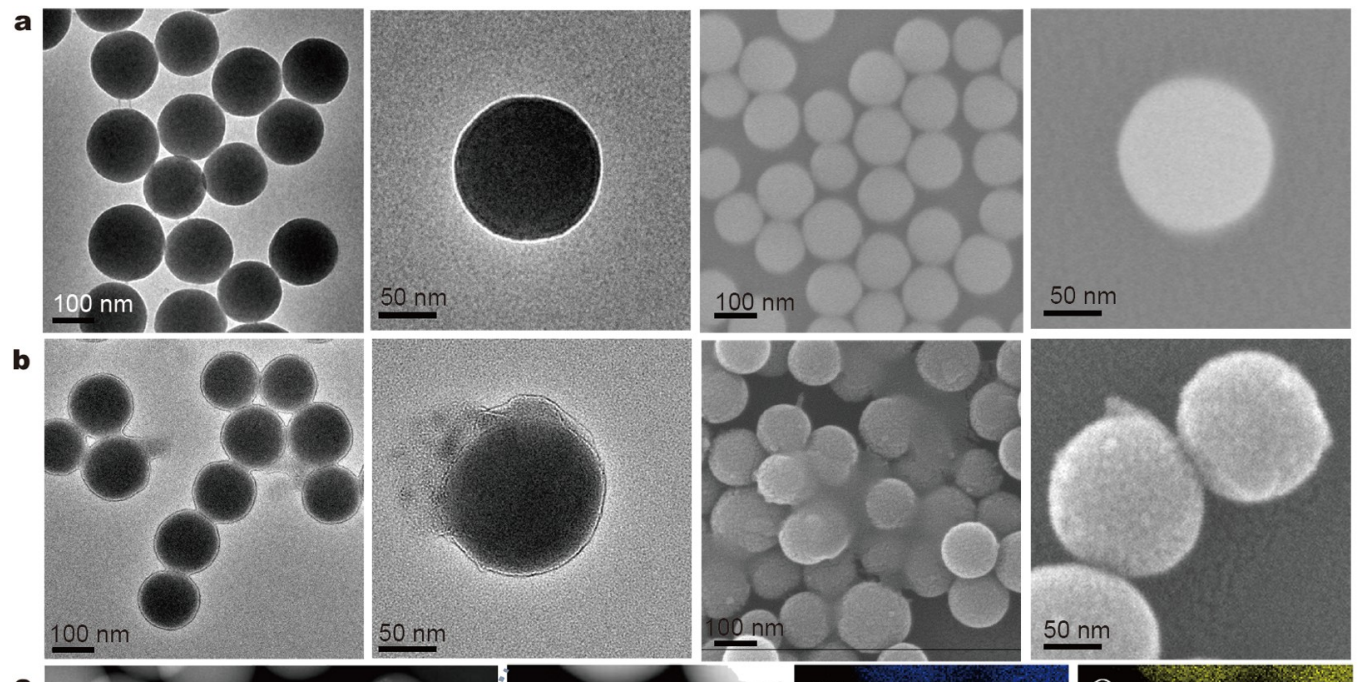

c
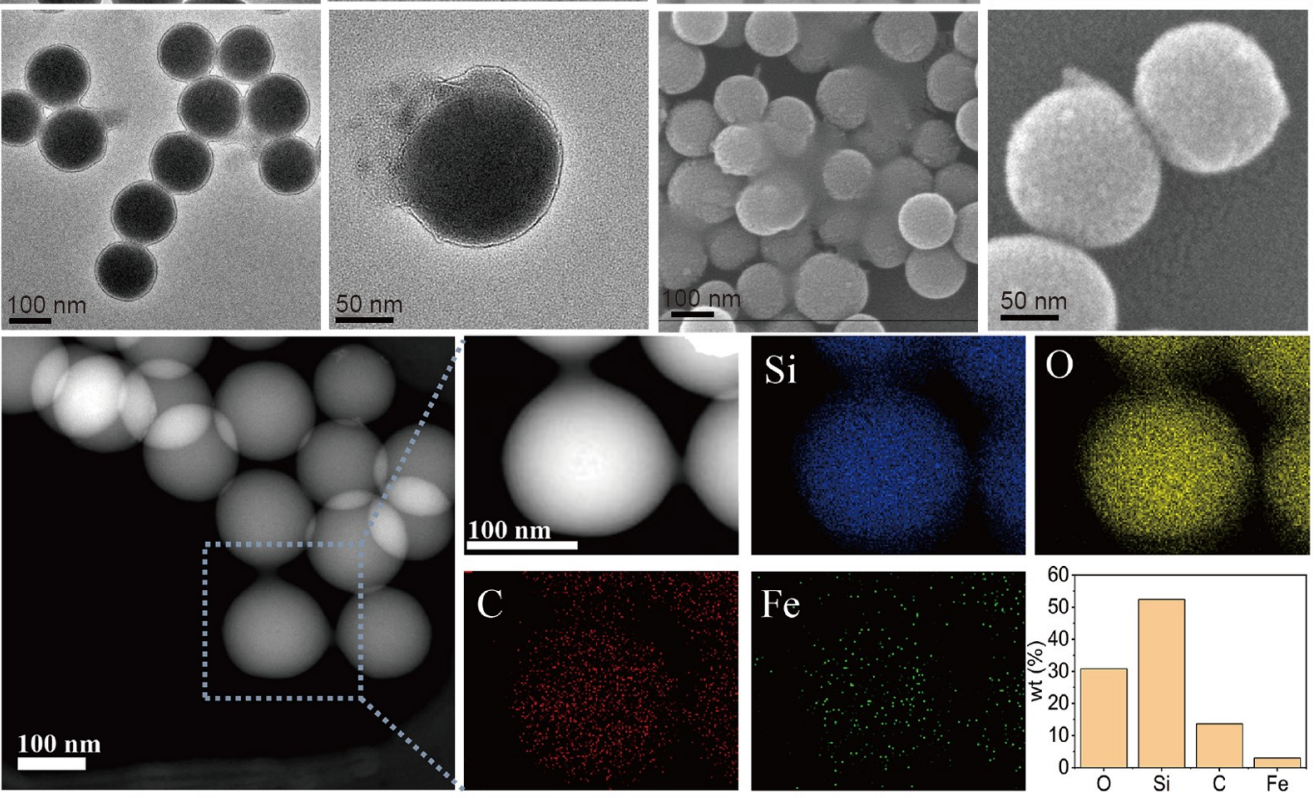

Figure 1 (a) SEM and TEM images of $\mathrm{SiO}_{2} @ \mathrm{MCSGs}^{\mathrm{ABTS}}$. (b) STEM image and the element mapping of $\mathrm{Si}, \mathrm{O}, \mathrm{C}$, and $\mathrm{Fe}$ of $\mathrm{SiO}_{2} @ M C S G s^{\mathrm{ABTS}}$. (c) The energy dispersive spectroscopic (EDS) analysis of the $\mathrm{SiO}_{2} @ \mathrm{MCSGs}^{\mathrm{ABTS}}$, and the weight percentages of $\mathrm{O}, \mathrm{Si}, \mathrm{C}$ and $\mathrm{Fe}$. 

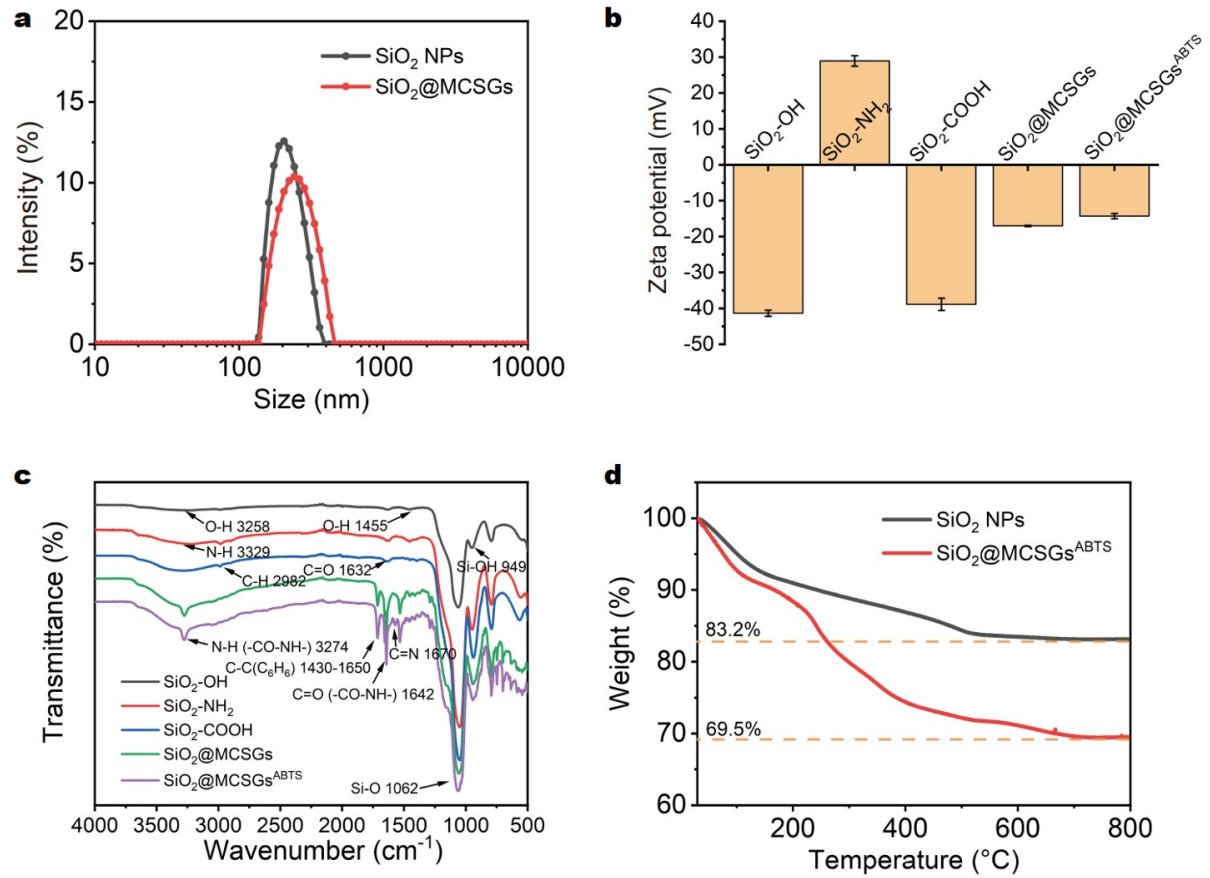

Figure 2 (a) DLS size distribution of $\mathrm{SiO}_{2} \mathrm{NPs}$ and $\mathrm{SiO}_{2} @ M C S G$ dispersed in water. (b) Zeta potentials of $\mathrm{SiO}_{2}-\mathrm{OH}, \mathrm{SiO}_{2}-\mathrm{NH} \mathrm{H}_{2}, \mathrm{SiO}_{2}-\mathrm{COOH}$, $\mathrm{SiO}_{2} @ M C S G s$ and $\mathrm{SiO}_{2} @ M C S G s^{\mathrm{ABTS}}$ dispersed in water. (c) FT-IR spectra of $\mathrm{SiO}_{2}-\mathrm{OH}, \mathrm{SiO}_{2}-\mathrm{NH}_{2}, \mathrm{SiO}_{2}-\mathrm{COOH}, \mathrm{SiO}_{2} @ M C S G s$ and $\mathrm{SiO} \mathrm{O}_{2} @ M C S G \mathrm{M}^{\mathrm{ABTS}}$. (d) $\mathrm{TG}$ analysis of $\mathrm{SiO}_{2} \mathrm{NPs}$ and $\mathrm{SiO}_{2} @ \mathrm{MCSG}^{\mathrm{ABTS}}$.

total weight loss as $1 \mathrm{~g} \mathrm{SiO}$ @MCSGs contained $0.305 \mathrm{~g}$ hydrogels (Fig. 2d). In addition, the DLS results (Fig. S5) showed that the $\mathrm{SiO}_{2} @$ MCSGs ${ }^{\mathrm{ABTS}}$ nanoplatform was stable in normal saline, Dulbecco's modified Eagle medium (DMEM) and simulate body fluid (SBF).

\section{Multienzyme-like activities of $\mathrm{SiO}_{2} @$ MCSGs}

The multienzyme-like (SOD and POD) activities of $\mathrm{SiO}_{2} @ M C S G s$ were further investigated as shown in Fig. 3, and a concise diagram of the catalytic reactions of $\mathrm{SiO}_{2} @ M C S G s$ with 3,3',5,5'-tetramethylbenzidine (TMB), ABTS and $\mathrm{O}_{2}^{-}$is shown in Fig. S6. Electron paramagnetic resonance (EPR) test confirmed the existence of $\mathrm{Fe}(\mathrm{III})$ intermediate in the catalytic process (Fig. 3a) [29]. Then, the POD-like activity of $\mathrm{SiO}_{2} @ M C S G$ was investigated by monitoring the absorbance change of substrate TMB at $652 \mathrm{~nm}$. As illustrated in Fig. 3b, compared with the TMB control group, $\mathrm{SiO}_{2} @ M C S G$ s could effectively catalyze TMB oxidation with the POD-like activity. In addition, with the decrease of $\mathrm{pH}$, the catalytic effect was enhanced, which is also beneficial for the responsive reaction in the acidic tumor microenvironment (Fig. S7). Then, the SOD-like activity of $\mathrm{SiO}_{2} @ M C S G s$ was further confirmed by WST-1 method (Fig. 3c) [31], and the absorbance change of the $\mathrm{SiO}_{2} @ M C S G$ group was inhibited compared with the control group. In addition,
Michaelis-Menten kinetics of $\mathrm{SiO}_{2} @ \mathrm{MCSG}$ and $\mathrm{Fe}(\mathrm{Lys})_{2}$ was investigated in Fig. $3 \mathrm{~d}$ and Fig. S8. At the same amount of active centers, the self-assembled supramolecular nanogel mimics $\mathrm{SiO}_{2} @ \mathrm{MCSG} \quad\left(k_{\mathrm{cat}} / k_{\mathrm{m}}\right.$ $=1.898 \mathrm{~s}^{-1} \mathrm{~L} \mathrm{~mol}^{-1}$ ) showed higher activities compared with that of free $\mathrm{Fe}(\mathrm{Lys})_{2}$ molecules $\left(k_{\mathrm{cat}} / k_{\mathrm{m}}\right.$ $=1.209 \mathrm{~s}^{-1} \mathrm{~L} \mathrm{~mol}^{-1}$ ), verifying that the enzyme-anchored self-assembled microstructures through noncovalent interactions can provide the favorable enzymatic microenvironment, similar to the biological ECM structure.

\section{In vitro $\mathrm{PA}$ effect}

As reported, the oxidized ABTS exhibited strong NIR absorption [32-34]. $\mathrm{SiO}_{2} @ M C S G{ }^{\mathrm{ABTS}}$ can tandem generate $\mathrm{H}_{2} \mathrm{O}_{2}$ intermediates by the SOD mimic activity and further oxidize the ABTS into its oxidized form with NIR absorption by the POD mimic activity. As shown in Fig. 4a, $\mathrm{SiO}_{2} @ M C S G s^{\mathrm{ABTS}}$ have the same absorption peak as ABTS at $342 \mathrm{~nm}$, which proves the successful load of ABTS. In addition, an absorption of nanodots in the NIR region can be observed after incubation with $\mathrm{H}_{2} \mathrm{O}_{2}$. And with the increase of $\mathrm{H}_{2} \mathrm{O}_{2}$ concentration from 5 to $50 \mu \mathrm{mol} \mathrm{L}^{-1}$ [35], the absorbance of $\mathrm{SiO}_{2} @ \mathrm{MCSGs}^{\mathrm{ABTS}}$ in the NIR region was significantly improved (Fig. 4b). Moreover, the absorbance of $\mathrm{SiO}_{2} @ M$ MCSGs ${ }^{\mathrm{ABTS}}$ in the NIR region has a certain linear relationship with the 

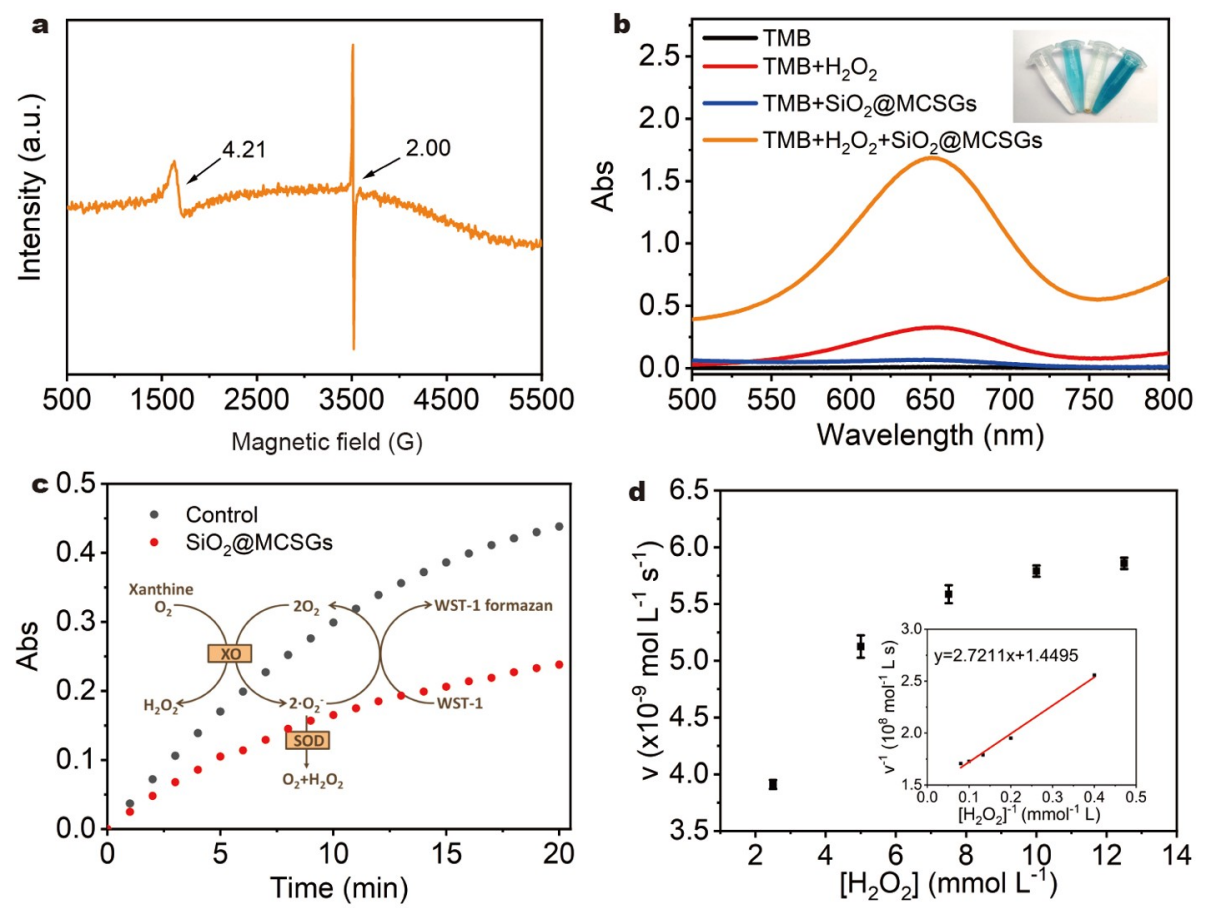

Figure 3 (a) Perpendicular-mode X-band EPR spectrum of the $\mathrm{Fe}(\mathrm{Lys})_{2} / \mathrm{H}_{2} \mathrm{O}_{2}$ system. (b) Typical UV-vis absorbance spectra showing POD-like activity of $\mathrm{SiO}_{2} @ M C S G s$. (c) SOD-like activity measured by the WST-1 method. (d) Michaelis-Menten kinetics and the double-reciprocal plots (inset) of POD activities.
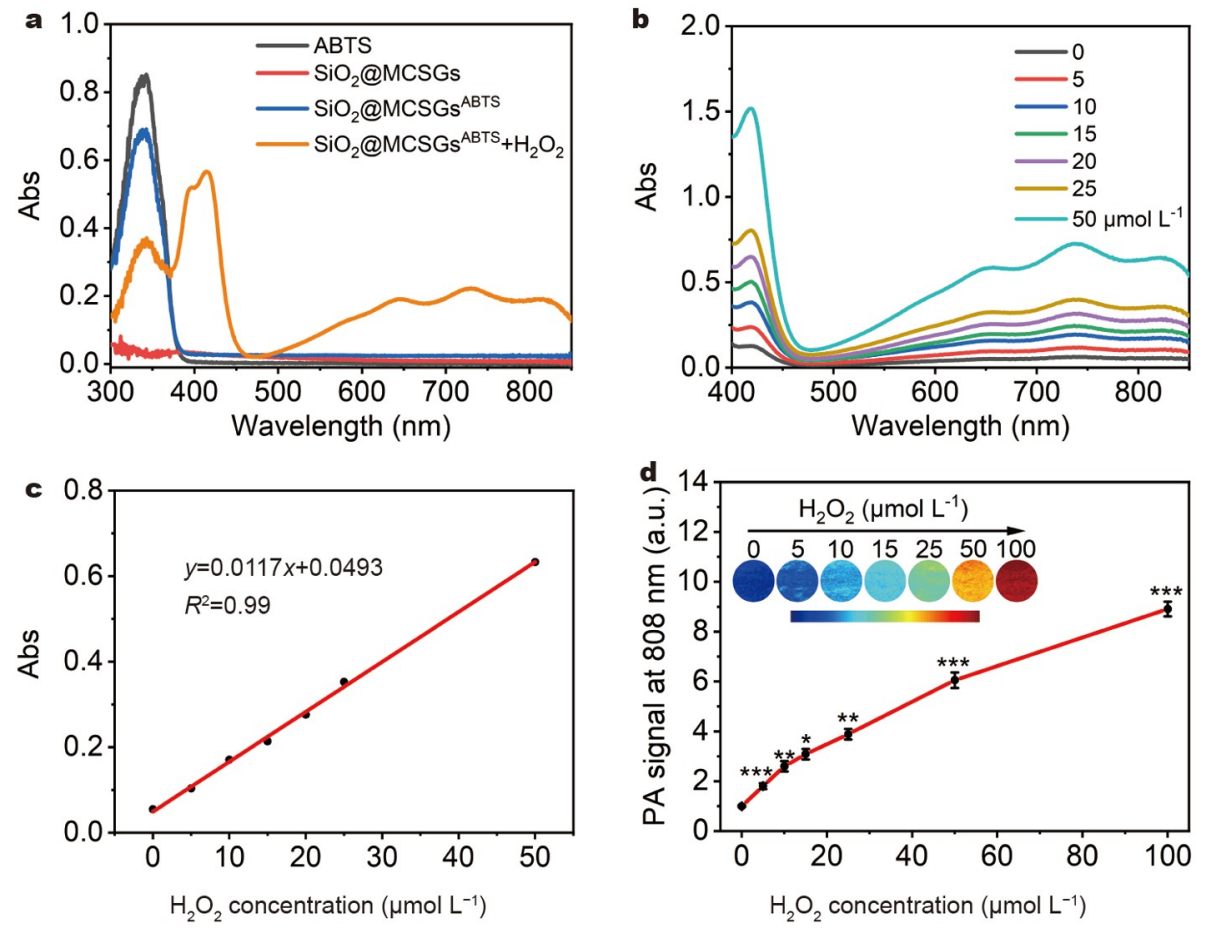

Figure 4 (a) The UV-vis absorption spectra of ABTS, $\mathrm{SiO}_{2} @ M C S G s$, and $\mathrm{SiO}_{2} @ M C S G{ }^{\mathrm{ABTS}}$ before and after $\mathrm{H}_{2} \mathrm{O}_{2}$ treatment. (b) The UV-vis absorption spectra of $\mathrm{SiO}_{2} @ M C S G s{ }^{\mathrm{ABTS}}$ before and after treatments with different concentrations of $\mathrm{H}_{2} \mathrm{O}_{2}\left(0-50 \mu\right.$ mol $\left.\mathrm{L}^{-1}\right)$. (c) The linear fitting curve between the $\mathrm{H}_{2} \mathrm{O}_{2}$ concentration and the absorbance at $808 \mathrm{~nm}$. (d) PA signal intensity of $\mathrm{SiO}_{2} @ M \mathrm{MCSGs}^{\mathrm{ABTS}}$ after treatments with different concentrations of $\mathrm{H}_{2} \mathrm{O}_{2}\left(0-100 \mu \mathrm{mol} \mathrm{L}{ }^{-1}\right)$ under 808 -nm laser irradiation. Inset: the corresponding PA images. $n=3,{ }^{* *} P<0.001,{ }^{* *} P<0.01,{ }^{*} P<0.05$ (compared with the previous group). 
concentration of $\mathrm{H}_{2} \mathrm{O}_{2}$ at $808 \mathrm{~nm}$ (Fig. 4c). Then, the in vitro PA imaging effect of $\mathrm{SiO}_{2} @ M C S G{ }^{\text {ABTS }}$ has been explored. As shown in Fig. 4d, the PA signal intensity increased with the increase of $\mathrm{H}_{2} \mathrm{O}_{2}$ concentration, and the PA imaging effect was positively correlated with the $\mathrm{H}_{2} \mathrm{O}_{2}$ concentration from 5 to $50 \mu \mathrm{mol} \mathrm{L}^{-1}$. Therefore $\mathrm{SiO}_{2} @ M C S G s^{\mathrm{ABTS}}$ can be potentially used for efficient bioresponsive PA imaging of tumor.

\section{In vivo PA imaging effect}

Before in vivo application, we studied the endocytosis and cytotoxicity of $\mathrm{SiO}_{2} @ M C S G s^{\text {ABTS }}$. As shown in Fig. S9, the green fluorescence from fluorescein isothiocyanate (FITC)-modified $\mathrm{SiO}_{2} @ M C S G s^{\mathrm{ABTS}}$ can be found inside the cells. Then, the cytotoxicity of $\mathrm{SiO}_{2} @ M C S G s^{\mathrm{ABTS}}$ to 3T3 and Hela cells was assessed by CCK- 8 assay and
Calcein AM/PI staining (Figs S10 and S11). It was found that $\mathrm{SiO}_{2} @ M C S G{ }^{\mathrm{ABTS}}$ show negligible cell cytotoxicity even at the concentration of $200 \mu \mathrm{g} \mathrm{mL}^{-1}$.

A schematic diagram of in vivo PA imaging by using $\mathrm{SiO}_{2} @ M C S G s^{\mathrm{ABTS}}$ is shown in Fig. 5a. The animal experiments in this study were conducted in accordance with the National Institutes of Health of China for the care and use of laboratory animals. All animal work was carried out under the guidance of Tongji University's Animal Care and Use Committee. Five-week-old female $\mathrm{BALB} / \mathrm{c}$ nude mice were ordered from Shanghai Meixuan Bio-tech company and Hela cells $\left(\sim 5 \times 10^{6}\right.$ cells $)$ suspended in phosphate buffered saline (PBS) $(100 \mu \mathrm{L})$ were injected into the right thigh of each mouse to establish a tumor model.

The 3D PA imaging was performed on the mice by
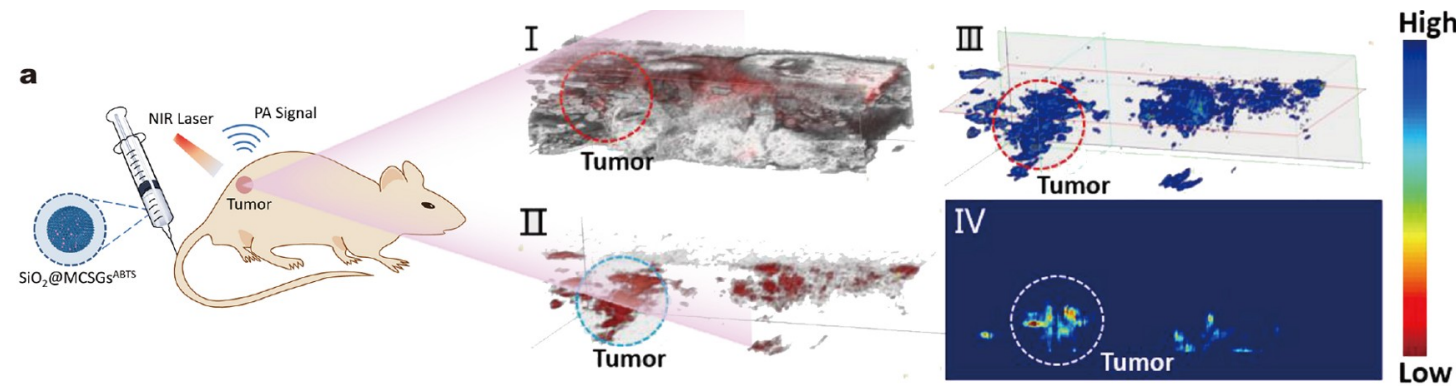

b

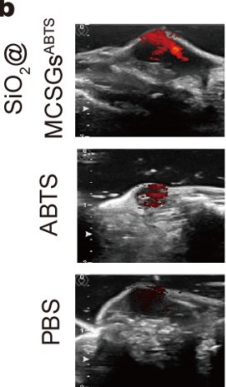

$0.25 \mathrm{~h}$

d

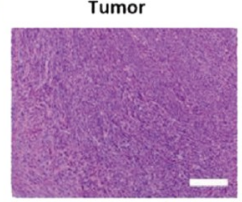

e

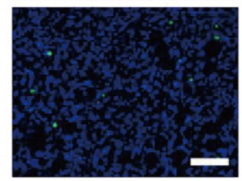

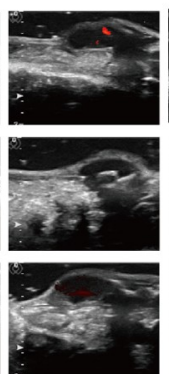

$0.5 \mathrm{~h}$
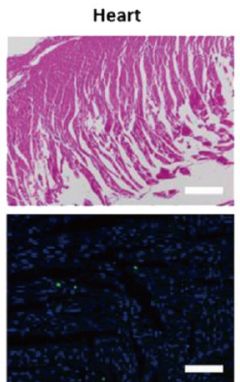
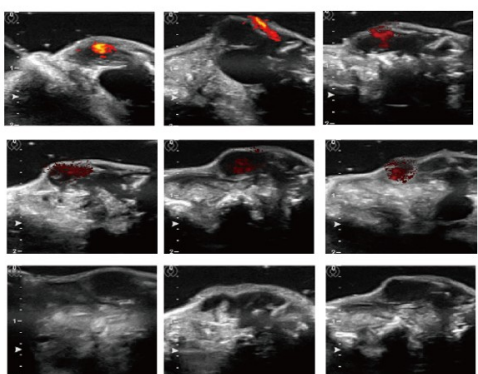

$2 \mathrm{~h}$

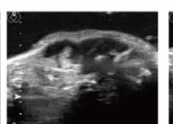

$4 \mathrm{~h}$

Liver
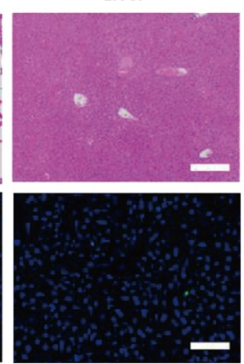

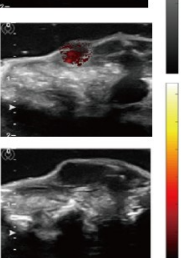

$6 \mathrm{~h}$
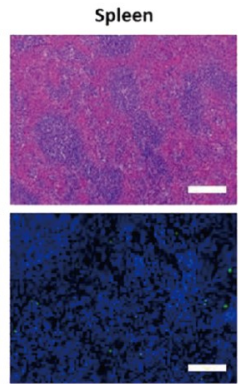

c

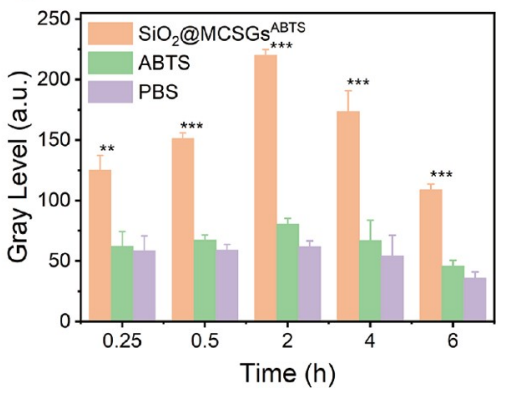

Lung
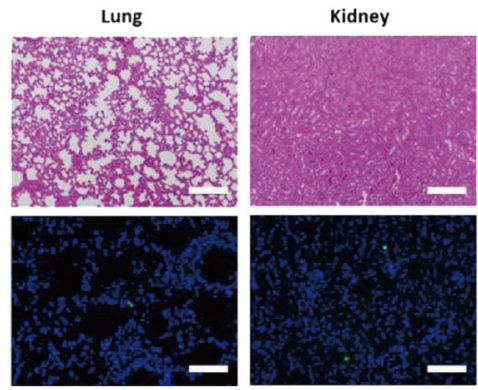

Figure 5 (a) Schematic illustration and 3D PA scanning image of Hela tumor-bearing mice by intravenous injection of SiO ${ }_{2} @ M C S G s^{A B T s}$. I: Ultrasonic PA fusion mode; II: PA mode; III: PA mode with pseudo color; IV: PA signal of one cross section. (b) In vivo PA images at different timepoints and (c) the corresponding PA signal intensities in the tumor region of $\mathrm{SiO}_{2} @ \mathrm{MCSGs}{ }^{\mathrm{ABTS}}$, ABTS and PBS group, respectively. $n=3,{ }^{* * *} P<$ $0.001,{ }^{* *} P<0.01$. (d) H\&E and (e) TUNEL-stained images of heart, liver, spleen, lung, kidney and tumor (nuclei were stained blue and apoptotic cells were stained green). Scale bar, $200 \mu \mathrm{m}$. 
intravenous injection of $\mathrm{SiO}_{2} @ M C S G s^{\mathrm{ABTS}}$. Results indicated that the PA signals in tumor areas were significantly stronger than those in other areas. Furthermore, as displayed in Fig. $5 b$ and $c$, the PA signal intensities in the tumor region of $\mathrm{SiO}_{2} @ \mathrm{MCSGs}{ }^{\mathrm{ABTS}}$ group increased significantly over time after intravenous injection. The maximum value was detected at $2 \mathrm{~h}$, and then it went down over time. As controls, the PA images of ABTS group and PBS group showed the negligible signal. The pharmacokinetics results reveal that the circulating half-life of $\mathrm{SiO}_{2} @ M C S G s^{\mathrm{ABTS}}$ is $1.48 \mathrm{~h}$ (Fig. S12). In addition, the main organs including heart, liver, spleen, lung and kidney were stained with hematoxylineosin ( $\mathrm{H} \& \mathrm{E})$ to evaluate the biocompatibility of $\mathrm{SiO}_{2} @$ MCSGs $^{\mathrm{ABTS}}$ in vivo. As shown in Fig. $5 \mathrm{~d}$, no tissue damage or inflammation was observed in any of the major organs. In addition, the results of TUNEL staining (Fig. 5e) also verified that there was no significant apoptosis in the tested area. It is indicated that the $\mathrm{SiO}_{2} @ M C S G{ }^{\mathrm{ABTS}}$ with the self-assembled mimics structure show high tandem enzymatic capability for the efficient responsive PA imaging of tumor.

\section{CONCLUSIONS}

In summary, bioinspired by the natural matrix-associated multienzyme assembled structure, we designed MCSGs with the self-assembly of di-lysine-coordinated iron $\left(\mathrm{Fe}(\mathrm{Lys})_{2}\right)$-functionalized peptide gelators by in situ amidation protonation reaction, which exhibited the tandem SOD and POD catalytic ability. Furthermore, the self-assembled nanogel mimics $\mathrm{SiO}_{2} @ M C S G s$ show higher activities $\left(k_{\text {cat }} / k_{\mathrm{m}}=1.898 \mathrm{~s}^{-1} \mathrm{~L} \mathrm{~mol}^{-1}\right)$ compared with free $\mathrm{Fe}(\mathrm{Lys})_{2}$ molecules $\left(k_{\text {cat }} / k_{\mathrm{m}}=1.209 \mathrm{~s}^{-1} \mathrm{~L} \mathrm{~mol}^{-1}\right)$, verifying that the enzyme-anchored self-assembled microstructures through noncovalent interactions can provide the favorable enzymatic microenvironment, similar to the biological ECM structure. Both the in vitro and in vivo results verified that $\mathrm{SiO}_{2} @ M C S G{ }^{\mathrm{ABTS}}$ demonstrated the effective PA imaging by the tandem enzymatic reaction. The high tandem efficiency exhibited by self-assembly $\mathrm{SiO}_{2} @ M C S G s$ mimics in this work leads to the exploration of design strategy and the applications of multienzyme mimics in further work.

\section{Received 2 March 2021; accepted 29 April 2021; published online 7 July 2021}

1 Whitesides GM, Mathias JP, Seto CT. Molecular self-assembly and nanochemistry: A chemical strategy for the synthesis of nanostructures. Science, 1991, 254: 1312-1319

2 Schnur JM. Lipid tubules: A paradigm for molecularly engineered structures. Science, 1993, 262: 1669-1676

3 Yang Z, Liang G, Xu B. Enzymatic hydrogelation of small molecules. Acc Chem Res, 2008, 41: 315-326

4 Gao Y, Zhao F, Wang Q, et al. Small peptide nanofibers as the matrices of molecular hydrogels for mimicking enzymes and enhancing the activity of enzymes. Chem Soc Rev, 2010, 39: 34253433

5 Mouw JK, Ou G, Weaver VM. Extracellular matrix assembly: A multiscale deconstruction. Nat Rev Mol Cell Biol, 2014, 15: 771785

6 Theocharis AD, Skandalis SS, Gialeli C, et al. Extracellular matrix structure. Adv Drug Deliver Rev, 2016, 97: 4-27

7 Vázquez-González M, Wang C, Willner I. Biocatalytic cascades operating on macromolecular scaffolds and in confined environments. Nat Catal, 2020, 3: 256-273

8 Wang H, Feng Z, Qin Y, et al. Nucleopeptide assemblies selectively sequester ATP in cancer cells to increase the efficacy of doxorubicin. Angew Chem Int Ed, 2018, 57: 4931-4935

9 Huang Z, Liu Y, Wang L, et al. Supramolecular assemblies mimicking neutrophil extracellular traps for MRSE infection control. Biomaterials, 2020, 253: 120124

10 Chen J, Zhao Y, Yao Q, et al. Pathological environment directed in situ peptidic supramolecular assemblies for nanomedicines. Biomed Mater, 2021, 16: 022011

11 Ding H, Cai Y, Gao L, et al. Exosome-like nanozyme vesicles for $\mathrm{H}_{2} \mathrm{O}_{2}$-responsive catalytic photoacoustic imaging of xenograft nasopharyngeal carcinoma. Nano Lett, 2019, 19: 203-209

12 Kreft O, Prevot M, Möhwald H, et al. Shell-in-shell microcapsules: A novel tool for integrated, spatially confined enzymatic reactions. Angew Chem Int Ed, 2007, 46: 5605-5608

13 Wang X, Li Z, Shi J, et al. Bioinspired approach to multienzyme cascade system construction for efficient carbon dioxide reduction. ACS Catal, 2014, 4: 962-972

14 Liu J, Postupalenko V, Lörcher S, et al. DNA-mediated self-organization of polymeric nanocompartments leads to interconnected artificial organelles. Nano Lett, 2016, 16: 7128-7136

$15 \mathrm{Hu} \mathrm{X}$, Zhang Y, Xie Z, et al. Stimuli-responsive polymersomes for biomedical applications. Biomacromolecules, 2017, 18: 649-673

16 Liu X, Formanek P, Voit B, et al. Functional cellular mimics for the spatiotemporal control of multiple enzymatic cascade reactions. Angew Chem Int Ed, 2017, 56: 16233-16238

17 Elani Y, Solvas XCI, Edel JB, et al. Microfluidic generation of encapsulated droplet interface bilayer networks (multisomes) and their use as cell-like reactors. Chem Commun, 2016, 52: 5961-5964

18 Comellas-Aragonès M, Engelkamp $\mathrm{H}$, Claessen VI, et al. A virusbased single-enzyme nanoreactor. Nat Nanotech, 2007, 2: 635-639

19 Patterson DP, Schwarz B, Waters RS, et al. Encapsulation of an enzyme cascade within the bacteriophage P22 virus-like particle. ACS Chem Biol, 2014, 9: 359-365

$20 \mathrm{Wu} \mathrm{Q}, \mathrm{He} \mathrm{Z}$, Wang X, et al. Cascade enzymes within selfassembled hybrid nanogel mimicked neutrophil lysosomes for singlet oxygen elevated cancer therapy. Nat Commun, 2019, 10: 240

21 Xu Y, Fei J, Li G, et al. Nanozyme-catalyzed cascade reactions for mitochondria-mimicking oxidative phosphorylation. Angew Chem Int Ed, 2019, 58: 5572-5576

22 Yan T, Li F, Tian J, et al. Biomimetic pulsating vesicles with both pH-tunable membrane permeability and light-triggered disassembly-re-assembly behaviors prepared by supra-amphiphilic helices. ACS Appl Mater Interfaces, 2019, 11: 30566-30574 
23 Wen M, Ouyang J, Wei C, et al. Artificial enzyme catalyzed cascade reactions: Antitumor immunotherapy reinforced by NIR-II light. Angew Chem, 2019, 131: 17586-17593

24 Shang Y, Liao Y, Ye Z, et al. Supramolecular protein glue to boost enzyme activity. Sci China Mater, 2019, 62: 1341-1349

25 Li Y, Sun P, Zhao L, et al. Ferric ion driven assembly of catalaselike supramolecular photosensitizing nanozymes for combating hypoxic tumors. Angew Chem Int Ed, 2020, 59: 23228-23238

26 Chivers PRA, Smith DK. Shaping and structuring supramolecular gels. Nat Rev Mater, 2019, 4: 463-478

27 Wu C, Zhang R, Du W, et al. Alkaline phosphatase-triggered selfassembly of near-infrared nanoparticles for the enhanced photoacoustic imaging of tumors. Nano Lett, 2018, 18: 7749-7754

28 Yin C, Wen G, Liu C, et al. Organic semiconducting polymer nanoparticles for photoacoustic labeling and tracking of stem cells in the second near-infrared window. ACS Nano, 2018, 12: 1220112211

29 Qi M, Pan H, Shen H, et al. Nanogel multienzyme mimics synthesized by biocatalytic ATRP and metal coordination for bioresponsive fluorescence imaging. Angew Chem Int Ed, 2020, 59: $11748-11753$

30 Qiao L, Wang X, Gao Y, et al. Laccase-mediated formation of mesoporous silica nanoparticle based redox stimuli-responsive hybrid nanogels as a multifunctional nanotheranostic agent. Nanoscale, 2016, 8: 17241-17249

31 Fan K, Xi J, Fan L, et al. In vivo guiding nitrogen-doped carbon nanozyme for tumor catalytic therapy. Nat Commun, 2018, 9: 1440

32 Fu Q, Zhu R, Song J, et al. Photoacoustic imaging: Contrast agents and their biomedical applications. Adv Mater, 2018, 1805875

33 Yang W, Shi X, Shi Y, et al. Beyond the roles in biomimetic chemistry: An insight into the intrinsic catalytic activity of an enzyme for tumor-selective phototheranostics. ACS Nano, 2018, 12: $12169-12180$

34 Chen $\mathrm{Q}$, Liang $\mathrm{C}$, Sun $\mathrm{X}$, et al. $\mathrm{H}_{2} \mathrm{O}_{2}$-responsive liposomal nanoprobe for photoacoustic inflammation imaging and tumor theranostics via in vivo chromogenic assay. Proc Natl Acad Sci USA, 2017, 114: 5343-5348

35 Szatrowski TP, Nathan CF. Production of large amounts of hydrogen peroxide by human tumor cells. Cancer Res, 1991, 51: 794798

Acknowledgements This work was supported by the National Natural Science Foundation of China (51773155 and 51873156), and the National Key Research and Development Program (2016YFA0100800 and 2018YFC1803100).

Author contributions Xia X, Wang X and Wang Q designed the studies and prepared the manuscript. Xia $\mathrm{X}$ accomplished most of the experiments including the preparation and characterization of the material, the detection of mimic enzyme activities, the cytotoxicity test and the animal experiments. Cheng Q, Gao Y and Liao J provided support for in vivo photoacoustic detection. Xia $\mathrm{X}$ wrote the original draft. Wang $\mathrm{X}$ and Wang Q revised the draft elaborately. Qi M, Han X, He X and Pan $\mathrm{K}$ made supporting contributions in data curation and formal analysis. All authors discussed the results and commented on the manuscript.

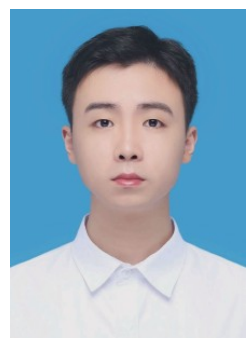

Xianmeng Xia is currently studying for a master's degree in the team of professor Qigang Wang, School of Chemical Science and Engineering, Tongji University. He received a bachelor's degree from Taiyuan University of Technology. His research interests focus on multifunctional enzymatic hydrogels for tumor imaging and therapy.

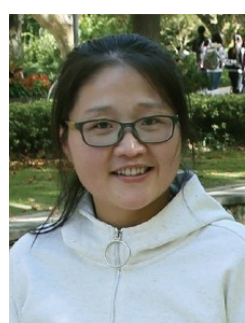

Xia Wang is an associate professor at Tongji University, Shanghai, China. Wang received her $\mathrm{PhD}$ degree from Shanghai Institute of Ceramics, Chinese Academy of Sciences (CAS) in 2013. Her research interests focus on the multifunctional enzymatic hydrogel composites for biomedical diagnosis and therapy.

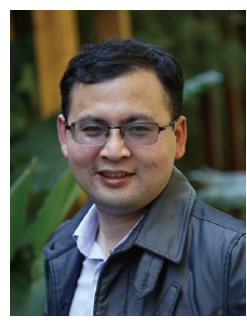

Qigang Wang is currently a professor at the School of Chemical Science and Engineering, Tongji University. He received his $\mathrm{PhD}$ degree from Shanghai Institute of Ceramics, CAS in 2005. He was the postdoctor of The Hong Kong University of Science and Technology, The University of Tokyo, and Riken from 2005 to 2011. His research interests focus on enzymatic polymerized methodology, printing/molding of fuctional hydrogel or nanogel, and ionic gel electrolyte designs for flexible electronics/bioelectronics.

\section{模拟多酶的自组装纳米凝胶构建及其生物响应性 级联催化诱导成像}

夏贤梦 ${ }^{1}$, 王霞 ${ }^{*}$, 韩小珂 ${ }^{1}$, 齐美园 ${ }^{1}$, 高雅 ${ }^{2,3}$, 廖江南 ${ }^{2,3}$, 何兴月 ${ }^{1}$, 潘开 ${ }^{1}$, 程茜 ${ }^{2,3}$, 王启刚 ${ }^{1 *}$

摘要 多酶复合物嵌合的自组装基质结构是生命体必要的组成部 分. 受此启发, 本工作基于原位酰胺化反应诱导质子化过程, 在纳米 界面上自组装二赖氨酸配位铁 $\left(\mathrm{Fe}(\mathrm{Lys})_{2}\right)$ 功能多肽单元, 设计、构 建了金属配合物基的超分子纳米凝胶 $\left(\mathrm{SiO}_{2} @ \mathrm{MCSG}\right)$ 材料. 由于其 高度分散的 $\mathrm{Fe}(\mathrm{Lys})_{2}$ 活性中心类似于天然基质相关多酶复合物的 高密度和纳米隔室化结构, 纳米凝胶模拟酶材料显示出优异的催 化效率. $\mathrm{SiO}_{2} @ \mathrm{MCSG}$ 同时呈现出超氧化物歧化酶(SOD)活性和过 氧化物酶(POD)活性, 且与游离 $\mathrm{Fe}(\mathrm{Lys})$, $_{2}$ 分子相比显示超活性性能. 负载底物 2,2 - 叠氮双-(3-乙基苯并塞唑啉-6-磺酸盐)(ABTS) 后, $\mathrm{SiO}_{2} @ \mathrm{MCSG}^{\mathrm{ABTS}}$ 可以通过SOD模拟酶性能将肿瘤微环境中的 $\mathrm{O}_{2}^{-}{ }^{-}$ 迅速转化为 $\mathrm{H}_{2} \mathrm{O}_{2}$ 中间体, 然后基于 $\mathrm{POD}$ 模拟活性级联催化氧化 ABTS 实现高效的肿瘤光声成像(PA). 具有多酶催化性能的MCSGs 材料显示出对病理区响应性酶催化成像研究的巨大潜力.

Conflict of interest The authors declare no conflict of interest.

Supplementary information Experimental details and supporting data are available in the online version of the paper. 